\title{
Don, juego y capital. Interpretaciones antropológicas de los intercambios de oro en Yves Klein y Joseph Beuys
}

\author{
Diana Angoso \\ Universidad Nebrija de Madrid \\ dangoso@nebrija.es
}

RESUMEN: Las relaciones sociales establecidas en torno al intercambio -don o mercancía- son especialmente complejas en la esfera del arte. Desde la década de los noventa, se ha incrementado el interés de artistas e historiadores por la antropología y etnografía, influyendo en las prácticas artísticas contemporáneas. El presente artículo aborda precisamente el periodo anterior a esta eclosión para confrontar conceptos antropológicos como el don y el juego en contextos artísticos. Tomando como modelo de estudio las acciones de dos artistas clave -Yves Klein y Joseph Beuys- en torno al intercambio del oro, se plantea hasta qué punto la antropología y el arte confluyen, cómo se diferencian las interpretaciones antropológicas de las artísticas y qué puntos tienen en común.

PALABRAS CLAVE: Arte contemporáneo; Antropología del arte; Don; Capital; Oro; Yves Klein; Joseph Beuys.

\section{Gift, Play and Capital. Anthropological Interpretations for the Exchange of Gold in Yves Klein and Joseph Beuys}

ABSTRACT: Social relations created through exchange -be it gift or commodity- are particularly complex in the sphere of art. Since the nineties, artists and art historians have increasingly expressed interest in anthropology and ethnography, influencing contemporary artistic practices. The present article explores precisely the period before this eclosion, to confront anthropological concepts such as gift and play in artistic contexts. Through the case studies of two key artists -Yves Klein and Joseph Beuys-and their actions involving the exchange of gold, this article explores the extent of confluences between anthropology and art, how artistic interpretations diverge from anthropological theories and to what extent these disciplines converge.

KEYWORDS: Contemporary Art; Anthropology of Art; Gift; Capital; Gold; Yves Klein; Joseph Beuys.

Recibido: 28 de febrero de 2018 / Aceptado: 10 de junio de 2018.

Hacia una antropología en el arte

Cuando Hal Foster publicó el artículo «El artista como etnógrafo» (1996), situó en el centro de los debates el «giro etnográfico» en el arte. Ese mismo año, otro historiador el arte, W.J.T. Mitchel (1996), abrió el campo de los estudios visuales a la antropología mientras que Hans Belting (2007) establecería una antropología de la imagen -Bild-Anthropologie- incorporando el cuerpo y la mente del espectador en la interpretación de la imagen. Cada uno de estos enfoques tomaba prestados conceptos clave de la antropología -o «conceptos viajeros» para decirlo a la manera de Mieke Bal-.

Por su parte, una nueva generación de antropólogos sociales (Coles, 2000, Schneider y Wright, 2005) se han interesado por explorar las confluencias entre arte y antropología, abriéndose al estudio material y sensual de las prácticas artísticas contemporáneas en el así denominado giro sensorial (sensory turn, Pink, 2009). En el presente artículo, se ha prestado especial atención a los estudios del antropólogo social Roger Sansi, que se ocupa del arte participativo y relacional de los años

Cómo citar este artículo: ANGOSO, Diana, «Don, juego y capital. Interpretaciones antropológicas de los intercambios de oro en Yves Klein y Joseph Beuys", Boletín de Arte-UMA, n. ${ }^{\circ}$ 39, Departamento de Historia del Arte, Universidad de Málaga, 2018, pp. 93-100, ISSN: 0211-8483, DOI: http://dx.doi.org/10.24310/BoLArte.2018.v0i39.4242 
noventa para trazar conexiones entre arte y antropología en torno a conceptos como el don y el agente participativo (2014a, 2014b).

Si los estudios anteriormente citados se centran en el periodo de la década de los noventa hasta nuestros días, este estudio abarca la época anterior, situando el foco en el ámbito de las relaciones sociales que se crean por medio del intercambio. Las acciones llevadas a cabo por Yves Klein (Niza, 1928-París, 1962) y Joseph Beuys (Krefeld 1922-Düsseldorf, 1986) confrontan dos tipos de intercambio ofreciendo la oportunidad para abordar las nociones de don, capital y juego en un territorio compartido por el arte contemporáneo y la antropología.

\section{El don en el arte}

En su clásico estudio de 1925 Ensayo sobre el don (2010), Marcel Mauss identifica las relaciones sociales y jerárquicas entre sociedades, la deuda y la reciprocidad del don. Frente a la idea surgida en el siglo XVIII del don libre y personal, Mauss reconoce las desigualdades jerárquicas de las comunidades. La distinción entre el espíritu del don y el de la mercancía generó un amplio debate en la antropología; los regalos -afirmaban unos- parten de un espíritu de sociabilidad, espontaneidad y reciprocidad, mientras que las mercancías son intercambios calculados, orientados al beneficio y al interés propio. Ahora bien, en su estudio sobre la vida social de las cosas, Appadurai (1986) puso el foco en la dimensión calculadora que todo tipo de intercambio conlleva. Para Appadurai, mercancía es cualquier cosa que se intercambia; sin embargo, existen distintos tipos de intercambio: trueque, regalos o el sistema monetario actual.

Las relaciones sociales establecidas en torno al intercambio son especialmente complejas en la esfera del arte. Una obra de arte es, por un lado, un don; por otro, un objeto artístico y una mercancía. Quien mejor ha sabido plasmar la «magia» del arte es Lewis Hyde en su libro The Gift, Creativity and the Artist in the Modern World (2007) [1979]. En dicho ensayo, Hyde identifica tres tipos de dones en el arte: el don de la creatividad que recibe el artista, el don como el encuentro entre el creador y la materia, y el don como la experiencia estética de quien disfruta del arte. Este tercer tipo de don ha gozado de un gran desarrollo en la crítica del arte, desde Dewey en Art as Experience (2005-1935) hasta Rancière y su noción de régimen estético (2013). Para Hyde esa experiencia estética es percibida por el receptor como un regalo, situándose así en una esfera diferenciada del objeto-mercancía. Esa esfera correspondería al «valor de uso», siguiendo la terminología marxista, frente al «valor de intercambio». Como señala Hyde, Marx identificó en los escritores ingleses del siglo XVII la diferencia entre worth, -«valor de uso»-, y value, -«valor de intercambio»-. Hyde argumenta que la diferencia entre value y worth, es decir, entre «valor de intercambio» y «valor de uso», es la distancia entre mercancía y arte (2007: 1314 y ss.).

En su reciente libro Art, Anthropology and the Gift, Sansi (2014b) identifica tres espíritus del don: como un intercambio voluntario entre iguales, como una reproducción de la jerarquía social y como una trasgresión (2014b, 88). Superando la tradicional desconfianza de los antropólogos hacia Kant, Sansi explica cómo para el filósofo alemán -y posteriormente para Schiller-, el juicio estético nace del don, pues sería el resultado de la voluntad del juego, mientras que el valor económico -la mercancía- es el resultado de una necesidad. Por tanto, la diferencia entre el capital -el valor económico de la mercancía- y el don radica en la voluntad de juego (2014b, pos. 1452-1600).

Nuestro estudio se centra en acciones que permiten un paso de un estado a otro, de don a mercancía, a través del arte y el juego. Tanto Zone de Sensibilité Picturale Immatérielle (1959, 1961, 1962) de Yves Klein, como Wandlung (1982) de Joseph Beuys se presentan como una suerte de estado liminal entre una esfera y otra.

\section{Quemar oro, tirar oro: intercambios rituales}

Cuando el artista francés Yves Klein propuso la cesión de Zone de Sensibilité Picturale Immatérielle a cambio de oro inició la mercantilización del gesto. Dentro del corpus de las obras del artista, las Zone pertenecían a la categoría de intangibles y, en su origen, suplementos a las exposiciones. Si en la exposición Le Vide (1958) exploró las posibilidades infinitas de la nada, con las Zone dio forma a un concepto de obra liberado del objeto, en otras palabras, inmaterial ${ }^{1}$. Efímeras por su propia naturaleza, las Zone pertenecían a la categoría de intangibles, y solo cobraban forma en el mo- 
mento de la cesión a cambio de oro. Para dotarlo de solemnidad, el artista estableció unas normas rituales para las transmisiones: las Zone de Sensibilité Picturale Immatérielle se completarían cuando el comprador quemase el recibo y el artista arrojase la mitad del oro en el mar, en el río o bien en un lugar de la naturaleza donde no pudiese ser recuperado [1].

En las Zone se plantea la siguiente disyuntiva: si el precio refleja el valor, el precio de una obra estimable debería estar fuera del mercado, imposible de comprar ${ }^{2}$. Pero el acto de vender es clave para validar la naturaleza de obra de arte, y esta contradicción fue resuelta por Klein negándose a vender por dinero; la única manera era renunciar al intercambio monetario, que devalúa la obra dándole un precio prosaico, a favor de un trueque que permite un intercambio manteniendo la pureza de la obra ${ }^{3}$. Al convertir el intercambio en trueque se introducen una suerte de conceptos rituales maussianos de don y contra-don, aunque, como se demostrará más adelante, la intencionalidad del intercambio y la participación en ambos es dispar.

Por otro lado, si se traduce el ritual kleiniano al discurso antropológico, se perciben paralelismos con los ritos agonísticos y de carácter votivo arcaicos. Siguiendo el estudio del sociólogo y filólogo Louis Gernet (1948) sobre la agalma, la noción mítica del valor en la antigua Grecia que asociaba ciertos objetos preciosos y brillantes con la magia y el poder, la acción de Klein podría entenderse como un ritual de sacrificio. Al igual que las inmersiones del oro en el Sena, en la antigua Grecia el rito del sacrificio solía tener lugar a través de una inmersión en el mar que reflejaba una consagración total del objeto precioso. En la teoría del sacrificio subyace la noción de una reciprocidad, de un don y contra-don (Gernet, 1948: 436). Este tipo de contrato o alianza consiste en un sistema primitivo de convenio y obligación entre el hombre y lo sagrado. Al arrojar un objeto sacrificial, este sirve como prenda de inmunidad; en algunas culturas, los sacrificios humanos eran una conquista mágica de la inmortalidad. Ahora bien, en los ritos de la antigua Grecia el sacrificio era total cuando la consumación de la cosa abandonada era completa. Sin embargo, en los traslados rituales de las Zone Yves Klein no arrojó todo el oro, incluso cuando el comprador quemaba el recibo.

Esta incongruencia por parte de Klein -que prometía inmaterialidad, pero conservaba parte del oro y eternizaba

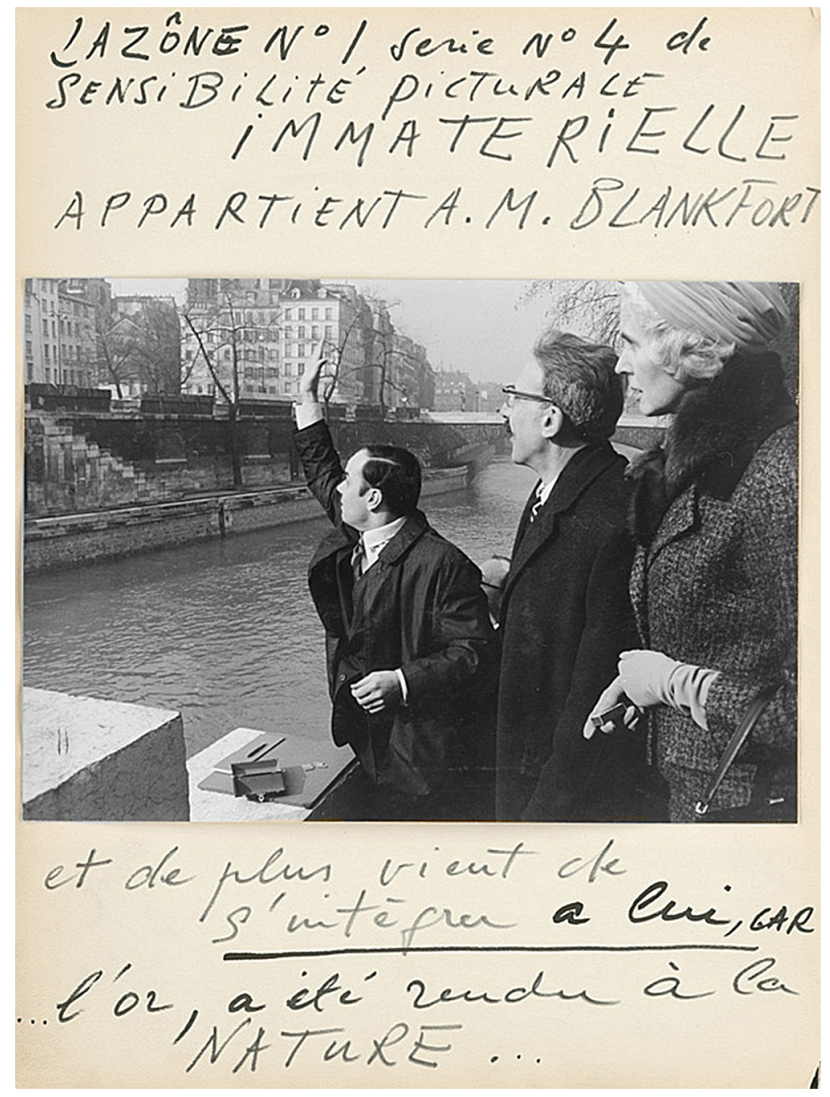

1. Yves Klein arrojando oro ante los Sres. Blankfort el 10 de febrero de 1962

el acto con fotografías que lo documentaban- causó cierta decepción en el coleccionista Michael Blankfort. «This was the first time I knew that Klein had arranged to have a photographer nearby. I confess I felt let down. An Immaterial -I thought- should be altogether immaterial. The making of a film record seemed a corruption of the artist's intent as well as the sensation of purity which had possessed me at the time» (Riout, 2010: 178).

Efectivamente, existe una disonancia entre las palabras y las acciones de Klein, entre su defensa de la calidad y sus actos mercantiles, especialmente en las ventas de las Zone de Sensibilité Picturale Immatérielle. Desde el momento en que las obras se venden, se activa una serie de mecanismos que otorgan credibilidad a las obras invisibles y las materializan: cheques, intercambio de objetos, documentos, fotografías, etc. Pero si tenemos en cuenta que es el acto de 
intercambio lo que abstrae el valor de uso de un objeto y sus cualidades y las transforma en cantidad, entonces resulta paradójico que sea precisamente el vender (el acto de intercambio económico) lo que materialice las obras inmateriales de Klein, convirtiendo una idea abstracta en algo concreto ${ }^{4}$. La explicación de esta aparente contradicción la encuentra Sophie Cras en la teoría del precio justo (2010a, 2010b). Según su hipótesis, Klein estaría introduciendo la noción medieval del "precio justo" a través de los contratos y de las ventas de las Zonas de Sensibilidad Pictórica Inmaterial. Para el artista francés, el valor es absoluto e intrínseco; entonces, la equiparación precio-valor se completa siguiendo la teoría del «precio justo» que consideraba la existencia de un orden divino de valores al que el precio -un instrumento humano, al fin y al cabo- debía ajustarse.

Otro elemento discordante en la acción de Klein fue la ceremoniosidad del rito, que unido a la ausencia del objeto material, provocó cierto desconcierto e, incluso, hilaridad. Pero ese elemento cómico no resta seriedad a la intención de Klein. Los estudios de Mauss y Huizinga (2008; 2010) reconocen un sustrato común entre el juego y lo sagrado, entre la esfera de obligación y la confianza recíproca, y la exhibición de potlatch que suponen muchas de las ceremonias arcaicas. Como afirma Huizinga, «la santidad y seriedad de una acción en modo alguno excluyen su cualidad lúdica» (2008: 96).

En una primera lectura, Klein parece reproducir el don maussiano respetando las desigualdades de las jerarquías sociales de la comunidad artística -de ahí la presencia de un crítico de arte, además del coleccionista en sus cesiones-. Ese intercambio de don es obligatorio y público, propio de las comunidades descritas por Mauss. Sin embargo, el beneficio no redunda en la comunidad sino en un individuo, el propio artista. Así, a pesar del vínculo espiritual en la acción, o incluso a pasar de su intencionalidad sagrada, Klein rompe la distinción entre dos esferas netamente separadas, la esfera del don y la esfera de la mercancía. Si como afirma Hyde siguiendo a Mauss, el don permite una participación de la persona, esa agencia participativa se quiebra en el momento en que Klein traslada la experiencia a la esfera de las mercancías. En otras palabras, Klein mercantiliza la experiencia artística.

Una parte de la extensa literatura crítica sobre Klein llegó a conclusiones similares. En clave post-marxista De Duve y Banai $(1994,2007)$ interpretaron las acciones del artista como un paso hacia al fin de la pintura y hacia la objetivación y mercantilización del arte. En palabras de De Duve, «Klein trabaja, pero quisiera que su existencia, y no su propia actividad, fuera el valor y el precio, que su estatuto de artista justificase su fama y probase su talento, que él tiene el monopolio de la creatividad y que el comprador (no el contemplador) tiene el monopolio del goce estético» (1994: 76). Mientras, otra escuela ha valorado la figura de Klein en cuanto artista del vacío, identificándolo con la filosofía zen, la cosmogonía rosacruz y, en general, la mística ${ }^{5}$. Para estos últimos, el vacío no es tal; es un vacío lleno de potencial regenerador y energético, «una plenitud indefinida que sirve (servía) como recurso ilimitado para revitalizarse» (Stich, 1994: 141).

\section{Regalo y Capital: Kunst = Kapital}

El intercambio más destructivo y, a la vez, fructífero surge de la mano del artista alemán Joseph Beuys. Wandlung -también conocida como Einschmelzung Der Zarenkrone (La fusión de la corona imperial)- parte del proyecto 7000 Eichen (7000 robles) (1982-1987), y consistía en plantar ese número de robles junto con piedras de basalto en la ciudad alemana de Kassel [2]. Cuando Beuys recibió en donación la réplica de la corona del zar Iván el Terrible con un considerable valor material, tomó la determinación de transformarlo. Wandlung (Transformación) supuso la destrucción de la corona para fundirla a una nueva forma, ante la vehemente oposición del gremio de orfebres y de la población de Kassel. Las láminas de oro deformadas por Bueys fueron fundidas a 1.110 grados y en estado líquido se vertieron en un molde con una forma muy sencilla: una liebre. Ante las protestas del público, Beuys mostró la liebre mientras exclamaba los nombres de célebres alquimistas -Paracelso, Raimundo Lulio, Agripa de Nettesheim-.

Friedenshase (Liebre de la paz) fue subastada alcanzando más del doble del precio estimado. De este modo, en Wandlung Beuys modificaba la forma de un objeto - de corona a liebre y sol- mientras creaba arte (y dinero) de forma mágica duplicando el valor monetario del objeto. Con todo este proceso, Beuys no solo le daba la espalda a la economía de mercado mientras ponía en práctica una economía real basada en otros valores, sino que además producía una plusvalía con la creatividad. 
La maleabilidad del oro que tanto interesaba a Beuys era una analogía del cambio que se producía en el sistema de valoración social pues según el pensamiento beuysiano -muy influido por Rudolf Steiner y la antroposofía- la clave de la transformación estaba en el calor, no solo el del fuego, sino principalmente el calor social. Para Beuys la dureza representaba la solidificación fruto del materialismo de la sociedad mientras que el calor y la energía conseguían transformar las sustancias espirituales. Por eso, el pensamiento beuysiano contrapone el principio de muerte -la racionalidad de la ciencia, lo duro, lo cristalino- frente al principio de vida, de la espiritualidad; en Wandlung las gemas frías y cristalinas, asociadas a la violencia y al materialismo, se convierten en símbolos de vida y fertilidad. Esa contraposición entre lo orgánico-inorgánico, lo cristalino y lo cálido continúa en 7000 Eichen, cuando junto al roble, orgánico, fértil y cálido, se coloca también el basalto, piedra dura y cristalina. Es el calor social y la energía lo que permite la transubstanciación. Una auténtica alquimia o, siguiendo la terminología de Beuys, un ejemplo de Kunst=Kapital.

El pensamiento económico de Beuys se sustentaba sobre una base radicalmente anti-materialista y democrática; pretendía conciliar la libertad individual de la sociedad actual con la espiritualidad del mundo arcaico. A partir de estas ideas, Beuys se plantea un objetivo: «(...) Quebrar el poder del dinero y del Estado. Esta es para el arte, por lo menos para mi arte, el que yo llevo a cabo, la (meta) más importante de todas» (Beuys y Lebrero Stals, 1983: 118). El artista alemán se atreve a ir al fondo de la cuestión para afirmar -con razónque el hombre corriente no se interesa por el arte, sino por el dinero. Pero si el hombre quiere ser auténticamente libre y llevar a cabo una autodeterminación se debe redefinir el dinero6; así es como se origina la fórmula Kunst = Kapital de Beuys:

Ha de aclarar una antropología razonable y práctica. También se trata de una necesidad espiritual que tenemos que ver relacionada con una acción permanente. Esto permitiría alcanzar el corazón del sistema existente -especialmente el corazón de su economía- pues la concepción expandida de arte está relacionada con la capacidad creativa de cualquiera. Aclara y hace comprensible para todo el mundo que el capital del mundo no es el dinero, tal y como lo entendemos, sino que el capital es la capacidad humana para la creatividad. Para la libertad y la autodeterminación en todos los lugares

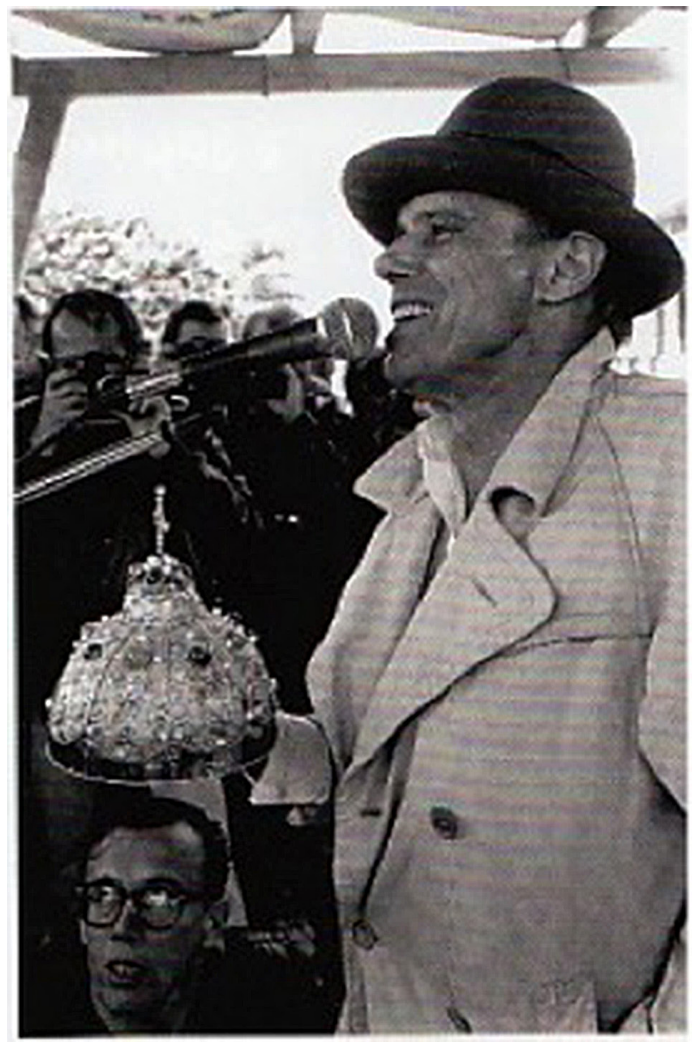

2. Joseph Beuys, acción Wandlung, 30 de junio de 1982

de trabajo... Esta idea puede llevar a una neutralización del capital y podría significar que el dinero no será por más tiempo una mercancía. El dinero se convertirá en un documento legal de derechos y obligaciones..., será real y llevará un sistema bancario democrático (Beuys y Klüser, 2006: 96).

Esos conceptos se pusieron en práctica en Wandlung, donde se originó un nuevo capital económico sustentado en donaciones cuya plusvalía de "creatividad artística» fue invertida en un proyecto de arte antropológico, 7000 Eichen. Aunque no menos importante fue el capital humano, el trabajo de los colaboradores que aportaron su tiempo y esfuerzo de forma voluntaria para plantar árboles. Así, asociaciones de vecinos, estudiantes de escuelas y universidades, artistas y ciudadanos practicaron el arte democrático juntos: todos podían colaborar, no era elitista, no estaba limitado a los muros de un museo; era un concepto ampliado del arte y, quizá lo más valioso: "todo hombre era un artista». 
Esa noción democrática entronca con el primer tipo de intercambio según Sansi, el don libre y voluntario entre iguales. Como señala Sansi, fue precisamente el pensador alemán Schiller quien en Cartas sobre la educación estética del hombre (1790-1792), definió la belleza y el juego como práctica de la libertad. Atento lector de Schiller, en 7000 Eichen Beuys ejercita una «utopía estética» Por eso, oponiéndose al utilitarismo económico, propicia la colaboración desinteresada de sujetos libres para la construcción de una comunidad por el bien común.

Con su fórmula Kunst = Kapital, Beuys demuestra cómo el arte no es dinero (capital), sino que el arte es el verdadero capital. Y continuando la lógica beuysiana: el pensamiento es nuestro verdadero capital.

\section{Conclusión}

Más allá de las diferencias entre artistas tan dispares como Klein y Beuys, en este artículo se han puesto de relieve dos visiones del don: el don maussiando como reproducción de

\section{Notas} crítica con la sociedad" (Stich, 1994: 145). suprasensibles, por improbable que parezca» (Arnaldo, 2000: 87). cambio» (Lütticken, 2013).

5 Stich, 1995; Arnaldo, 2000; McEvilley, 2010; Riout, 2010; Ottmann, 2010. jerarquías sociales y el don libre de Schiller como un intercambio entre iguales. En el primero, Klein parece respetar las normas maussianas de intercambios de dones, reproduciendo las jerarquías de la comunidad (coleccionista, crítico, artista). Las acciones cobran sentido solo dentro de los límites del mundo del arte, enfatizando la autonomía del arte frente a la sociedad. Sin embargo, Klein acaba quebrando esa esfera contenida del arte para mercantilizar la experiencia estética. Con sus cesiones, transforma el valor de uso en valor de cambio, el arte en mercancía.

Mientras, la acción de Beuys, siguiendo la propuesta schilleriana, se lleva a cabo como un intercambio de iguales, libre y voluntariamente, en la que intervienen agentes de la sociedad (donantes, estudiantes, cuidadanos). Rompiendo los estrictos límites de la comunidad artística, el artista alemán se abre a la sociedad, creando comunidad. Su ambición era transformar la sociedad por medio de un auténtico arte antropológico. En lugar de representar las relaciones sociales, Beuys proponía crear comunidad, fomentando las transformaciones y relaciones reales.

1 Stich describe la situación de la década de los cincuenta, cuando convivía el recuerdo de la guerra y la escasez con el consumismo y la producción en masa proveniente de Estados Unidos. «(Klein) al centrarse en lo inmaterial o espiritual, se alejaba de las cosas como medida de valor y de esta forma ofrecía una manera de asumir la reciente desesperación por la destrucción de la propiedad y el presente deseo de consumo. Una generación de poetas y artistas Beat estaban denunciando el materialismo y defendiendo la espiritualidad en ese mismo momento en Estados Unidos, aunque su protesta era más abierta y explícitamente

2 En este sentido resulta útil citar la descripción de Karl Marx del dinero: «Nominalmente el oro no tiene precio, no porque tenga un valor auténtico en sí mismo, sino que, como dinero, no tiene ningún valor. En cambio, expresa cierto quantum de su propio material; su propia determinación cuantitativa está impreso en ella". MARX, Karl, Grundrisse der Kritik der poetischen Ökonomie, borrador 1857/58, Berlin, 1971, p. 53, citado por Rübel, $2012: 78$.

3 Así lo declara en el Manifiesto del Hotel Chelsea: «El significado de las zonas cromáticas suprasensibles, surgidas de las profundidades del vacío que yo dominaba por entonces, era verdaderamente material. Puesto que daba por imposible comprar simplemente con dinero tales zonas cromáticas suprasensibles, pedí por el más valioso elemento de lo suprasensible el más valioso elemento de lo material, una barra de oro. Vendí un gran número de estos estados pictóricos

4 «El intercambio económico abstrae el valor de uso de un objeto y por lo tanto sus cualidades, transformándolas en pura cantidad en el momento del inter-

6 Lütticken escribe: «For Beuys, the problem was that money had become a commodity, and therefore an object of speculation. Money should never be treated as a commodity; it should instead be a legal document (Rechtsdokument) that can be used as a regulatory instrument. Money, in other words, should not be seen as belonging to an "autonomous" economic system; it is a social entity. In a contentious 1984 discussion with economists in which Beuys repeated his notion of money as a legal title in a mantra-like manner, he joined the banker and author Johann Philipp Bethmann in attacking the established position that money can be adequately defined by its threefold function: universal means of exchange, calculation unit, and device for storing value» (Lütticken, 2013). 


\section{Bibliografía}

APPADURAI, Arjun (1986), «Introduction: Commodities and the Politics of Value», The Social Life of Things, Cambridge University Press, Cambridge, pp. 3-63.

ARNALDO ALCUBILLA, Javier (2000), Yves Klein, Nerea, Hondarribia.

BAL, Mieke (2009), Conceptos viajeros en las humanidades. Una guía de viaje, CENDEAC Murcia.

BANAI, Nuit (2007), «Rayonnament and the Ready-made: Yves Klein and the End of Painting», RES: Anthropology and Aesthetics, vol. 51, Primavera, pp. 202-215.

BELTING, Hans (2007), Antropología de la imagen, Katz, Madrid y Buenos Aires.

BEUYS, Joseph y KLÜSER, Bernd (ed), (2006), Ensayos y entrevistas, Síntesis, Madrid (trad. de Miguel Salmerón).

BEUYS, Joseph, La fusión de la corona imperial (Einschmelzung Der Zarenkrone). [Vídeo documental]. En: <http://www.youtube.com/ watch?v=60kSx-3qQh0> (fecha de consulta: 23-5-2018).

BEUYS, Joseph; LOERS, Veit; WITZMANN, Pia (1993), Joseph Beuys. Documenta. Arbeit. [Cat. Exp.]. Museum Fridericianum Kassel, Edition Cantz, Kassel.

BEUYS, Joseph y LEBRERO STÄLS, José (1983), «El Arte no existe», Lápiz, n. 27, pp. 116-22.

COLES, A. (ed.) (2000), Site-Specificity: The Ethnographic Turn, Blackdog Publications, Londres.

BERNÁRDEZ SANCHÍS, Carmen (1999), Joseph Beuys, Nerea, Hondarribia.

BUCHLOH, Benjamin (1980), «Beuys: The Twilight of the Idol, Preliminary Notes for a Critique», Artforum, vol. 18, enero, pp. 35-43.

CRAS, Sophie (2010), «De la valeur de l'oeuvre au prix du marché: Yves Klein à l'épreuve de la pensée économique», Marges, Revue d'art contemporaine, n. ${ }^{\circ} 11$, en <http://journals.openedition.org/marges/446> (fecha de consulta: 25-5-2018).

- (2010) «The just price for a work of art according to Yves Klein: "Sketch and broad lines" of an economic system", Arts \& Societé Centre d'Histoire de Sciences Po, en: <http://www.artsetsocietes.org/a/a-cras.html> (fecha de consulta: 31-10-2013).

DEWEY, John (2005), Art as Experience, Penguin, Nueva York.

DUVE, Thierry de (1994), "Yves Klein o el comerciante muerto", 3 ZU Revista d'arquitectura, n. ${ }^{\circ}$ 2, 1994, pp. 76-85.

FOSTER, Hal (1996), «El artista como etnógrafo», El retorno de lo real, Akal, Madrid, pp. 175-207.

GERNET, Louis (1948), «La notion mythique de la valeur en Grèce», Journal de Psychologie, oct.-dic., pp. 415-462.

HYDE, Lewis (2007-1979), The Gift. Creativity and the Artist in the Modern World, Vintage Books, Nueva York.

HUIZINGA, Johan (2008-1938), Homo ludens, Alianza, Madrid.

DIA FOUNDATION (2005), [Nota de prensa], «7000 Oaks, Statements by Joseph Beuys», en: <http://web.mit.edu/allanmc/www/cookebeuys.pdf> (fecha de consulta: 22-5-2018).

KLEIN, Yves (2003-1959), Le Dépassement de la problematique de l'art et autres écrits, SICHÈRE, Marie-Anne; SEMIN, Dider (eds.), École nationale superieur des Beaux-Arts, París.

KUSPIT, Donald B. (1984), «Beuys: Fat, Felt and Alchemy», The Critic as Artist: The Intentionality of Art, UMI Research Press, Ann Arbor, Michigan, pp. 345-58.

LEARY, Timothy O’ (1996), «Fat, Felt and Fascism. The Case of Joseph Beuys», Literature \& Aesthetics, vol. 16, pp. 91-104.

LÜTTICKEN, Sven, «Inside Abstraction», e-flux Journal (\#38), en <https://www.e-flux.com/journal/38/61196/inside-abstraction/> (fecha de consulta: 23-5-2018).

MAUSS, Marcel (2010-1925), Ensayo sobre el don. Forma y función del intercambio en las sociedades arcaicas, Ed. Conocimiento, Buenos Aires y Madrid.

McEVILLEY, Thomas (1986), «Hic Jacet Beuys», Artforum, vol. 24, n. 9, mayo 1986, pp. 130-131.

- (2010), Yves the Provocateur: Yves Klein and Twenty-Century Art, McPherson\&Company, Nueva York.

MITCHEL, W.J.T. (1996), «What do Pictures Really Want?», October, n. ${ }^{\circ} 77$, pp. 71-82.

OTTMANN, Klaus (2010), Yves Klein. Obras y escritos, Ediciones Polígrafa, Barcelona.

PINK, Sarah (2009), Doing Sensory Ethnography, SAGE Publications, Londres. 
RANCIÈRE, Jacques (2013), Aisthesis: escenas del régimen estético del arte, Bordes Manantial, Buenos Aires.

RIOUT, Denys (2010), Yves Klein: Expressing the Immaterial, Éditions Dilecta, París.

RÜBEL, Dietmar (2012), «Gold \& Ashes. This Side of Art and Beyond» en KRÖGER, Michael y SCHLOEN, Ann (eds.), Ashes and Gold. A World's Journey, Marta Herford / Stiftung Museum Schloss Moyland, Herford, Marta Herdford, pp. 74-83.

RUTTEN, Kris; DIENDEREN, An van; SOETAERT, Ronald (2013), «Revisiting the Ethnographic Turn in Contemporary Art», Critical Arts, n. ${ }^{\circ}$ 27, pp. 459-473.

SANSI, Roger (2014a), «Arte, don y participación», Ankulegi, n. ${ }^{18}$, pp. 13-28.

- (2014b), Art, Anthropology and the Gift, Bloomsbury Academic, Edición Kindle.

SCHILLER, Friedrich (1990), Cartas sobre la educación estética del hombre (traducción de K. Feijóo y Jorge Seca), Anthropos, Barcelona. SCHNEIDER, Arnd; WRIGHT, Christopher (eds.) (2005), Contemporary Art and Anthropology, Berg Publishers, Oxford.

STICH, Sidra (1994), Yves Klein, Cantz Verlag Ostfilder. 